\section{Final diagnosis}

Actinomycosis associated with pilonidal abscess of the penis.

1 Bervar M, Manojlovic D, Ceramilac A. Pilonidal sinus of the penis. Vojnosanit Pregl 1968; 25: $199-200$ 2 Rashid AM, Williams RM, Parry D, Malone PR. Actino1992; 148: 405-6

3 Ohtsuka H, Arashiro K, Watanabe T. Pilonidal sinus of the axilla: report of five patients and review of the literature. Ann Plast Surg 1994; 33: 322-5.

4 Smith TE. Anterior or perineal pilonidal cysts. $\mathcal{F} A M A 1948$; 136: 973

Khan F, Fisher R. Pilonidal sinus in an amputee. $f$ R Army Med Corps 1991; 137: 88-9.
Keywords: actinomycosis, pilonidal cyst, penile disease

6 Patey DH, Currey RC. Pilonidal sinus presenting in the suprapubic region of a woman. Lancet 1962; 1: 620

7 Palmer E. Pilonidal cyst of the clitoris. Am $\mathcal{F}$ Surg 1957; 93: 133.

8 Anderson AW. Hair extracted from an ulcer. Boston Med Surg ₹ 1847; 36: 74 .

Hodges RM. Pilonidal sinus. Boston Med Surg 7 1880; 103: 485

10 Brearly R. Pilonidal sinus; a new theory of origin. Br f Surg 1955; 43: 62 .

\title{
Facial swelling in a patient with sarcoidosis
}

\author{
MJ Ledson, MC Walton, CRK Hind
}

A 50-year-old woman was referred with a six-week history of shortness of breath on exertion, and swelling of her arms and face. Thirty months earlier, an incidential chest X-ray had shown right hilar and mediastinal lymphadenopathy with clear lung fields (figure 1). She was a nonsmoker whose cousin had recently been diagnosed as having pulmonary sarcoidosis. Heaf and Kveim tests had been performed and were negative.

She was followed up for one year in which time serial chest $\mathrm{X}$-rays remained unchanged. At this point, a nasal biopsy was performed and was reported as showing 'numerous epithelioid granulomas consistent with sarcoidosis'. Once again, serial chest X-rays were performed which remained unchanged for a further 16 months. At the time of referral, she had been on prednisolone therapy ( $45 \mathrm{mg}$ daily) for eight weeks. A fine needle aspiration of a supraclavicular lymph node performed the week before referral had been 'consistent with sarcoidosis'. Her chest $\mathrm{X}$-ray on referral is shown in figure 2 .

Royal Liverpool and Broadgreen University Hospital Trust, Prescot Street, Liverpool L7 8XP, UK

MJ Ledson

MC Walton

CRK Hind

Correspondence to Dr CRK Hind

Accepted 24 January 1996

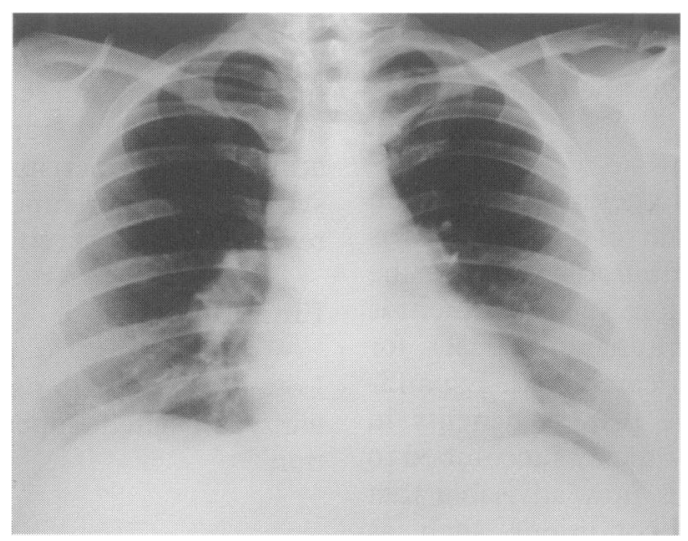

Figure 1 Chest X-ray 30 months earlier

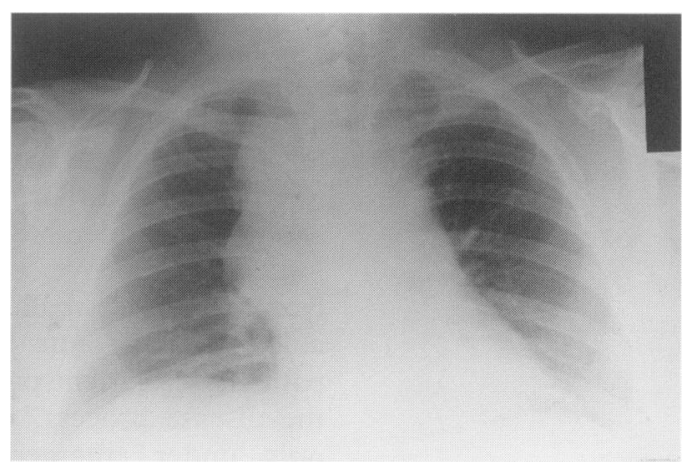

Figure 2 Chest X-ray at time of referral 


\section{Answers}

\section{QUESTION 1}

The two most probable underlying diagnoses are sarcoidosis and lymphoma.

\section{QUESTION 2}

These diagnoses may be linked by 'sarcoid' reactions to a lymphoma and an increased incidence of lymphoma in patients with sarcoidosis. Epithelioid-cell tubercles of sarcoid type may be found in a variety of tissues. These 'sarcoid reactions' can be associated with malignant disease or foreign bodies (eg, talc). In the case of lymphoma, these granulomata may be found both in tissues directly involved by the lymphoma as well as uninvolved tissue (eg, in the marrow). ${ }^{1}$ The histology of local sarcoid reactions may be indistinguishable from that of generalised sarcoidosis, and may be so extensive within an affected lymph node as to be misleading. Diagnosis depends upon searching for evidence of granulomas at other sites, and for possible causes of a local reaction.

Many studies have shown an increased incidence of malignant disease in patients with sarcoidosis. In one study of 2544 patients, malignant lymphoma occurred 11 times more frequently than expected. ${ }^{2}$ It has been postulated that an intact immume apparatus is one of the conditions necessary to prevent or limit the development of malignant tumours.

\section{QUESTION 3}

Superior vena cava obstruction is responsible for the swelling of the face and arms. Superior vena cava obstruction due to lymphoma is well recognised. Only a small number of cases of vena cava obstruction have been recorded in the literature associated with sarcoidosis. Thoracic CT scanning in our patient revealed narrowing of the superior vena cava (figure 3) due to the extraluminal lymphadenopathy.

\section{QUESTION 4}

Chemotherapy and radiotherapy. Irradiation has long been the mainstay of treatment. It is now recognised that accurate diagnosis of the aetiology is preferable before such treatment is initiated. Effective chemotherapy exists for lymphoma and small cell carcinoma. Expandable metallic stents have proven benefits in patients who, in the past, quickly succumbed to the disease process. ${ }^{4}$ It is now advisable that only under emergency conditions such as laryngeal or cerebral oedema should irradiation proceed without a formal diagnosis.

1 Brinckner H. Sarcoid reactions in Hodgkins disease and other malignant lymphomata. Br $\mathcal{F}$ Cancer 1972; 26: 120.

2 Brinckner $H$, Wilbeck $E$. The incidence of malignant tumours in patients with respiratory sarcoidosis. $\mathrm{Br} \mathcal{F}$ Cancer 1971; 29: 247 .

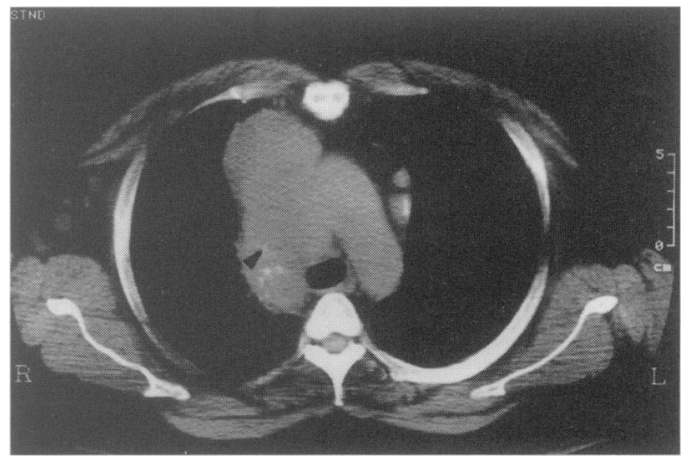

Figure 3 Thoracic CT scan showing compression of superior vena cava (arrowed) by mediastinal lymph nodes

\section{Superior vena cava obstruction}

Symptoms and signs

- conjunctival oedema

- visual disturbance

- headache

- dilatation of collateral veins of upper thorax and neck

- alteration in conscious level

Causes

- bronchial carcinoma $(75 \%)$

- lymphoma

- rarer causes: sarcoidosis, retrosternal thyroid, aortic aneurysm, fibrosing mediastinitis

\section{Discussion}

This woman underwent an open biopsy of a right supraclavicular lymph node. This revealed a low grade B cell non-Hodgkin's lymphoma. She underwent a course of combination chemotherapy (cyclophosphamide, adriamycin, vincristine, prednisolone). The symptoms of her superior vena cava syndrome resolved within seven days.

\section{Final diagnosis}

Low-grade B cell non-Hodgkin's lymphoma with associated superior vena cava obstruction.

Keywords: lymphoma, sarcoidosis, superior vena cava obstruction

3 Hunting T. Causes and management of superior vena cava syndrome Oncology 1993; 7: 61-8.

4 Jackson JE, Brooks DM. Stenting of superior vena cava obstruction. Thorax 1995; 50 (suppl 1): $531-6$. 